\title{
A C-Terminal Domain Directs Kv3.3 Channels to Dendrites
}

\author{
Qingwei Deng, ${ }^{1 \star}$ Asim J. Rashid, ${ }^{1 \star}$ Fernando R. Fernandez, ${ }^{2}$ Ray W. Turner, ${ }^{2}$ Leonard Maler, ${ }^{3}$ and Robert J. Dunn ${ }^{1}$ \\ ${ }^{1}$ Department of Neurology and Neurosurgery, Centre for Research in Neuroscience, McGill University Health Research Institute, Montreal, Quebec, Canada

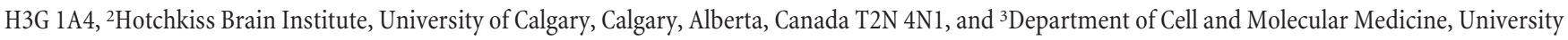 \\ of Ottawa, Ottawa, Ontario, Canada K1H 8M5
}

\begin{abstract}
Pyramidal neurons of the electrosensory lateral line lobe (ELL) of Apteronotus leptorhynchus express Kv3-type voltage-gated potassium channels that give rise to high-threshold currents at the somatic and dendritic levels. Two members of the Kv3 channel family, AptKv3.1 and $A p t \mathrm{Kv} 3.3$, are coexpressed in these neurons. AptKv3.3 channels are expressed at uniformly high levels in each of four ELL segments, whereas AptKv3.1 channels appear to be expressed in a graded manner with higher levels of expression in segments that process high-frequency electrosensory signals. Immunohistochemical and recombinant channel expression studies show a differential distribution of these two channels in the dendrites of ELL pyramidal neurons. AptKv3.1 is concentrated in somas and proximal dendrites, whereas $A p t \mathrm{Kv} 3.3$ is distributed throughout the full extent of the large dendritic tree. Recombinant channel expression of AptKv3 channels through in vivo viral injections allowed directed retargeting of $A p t \mathrm{Kv} 3$ subtypes over the somadendritic axis, revealing that the sequence responsible for targeting channels to distal dendrites lies within the $\mathrm{C}$-terminal domain of the AptKv3.3 protein. The targeting domain includes a consensus sequence predicted to bind to a PDZ (postsynaptic density-95/Discs large/zona occludens-1)-type protein-protein interaction motif. These findings reveal that different functional roles for Kv3 potassium channels at the somatic and dendritic level of a sensory neuron are attained through specific targeting that selectively distributes Kv3.3 channels to the dendritic compartment.
\end{abstract}

Key words: potassium channels; dendrites; targeting; Kv3; electrosensory; gene delivery; Semliki Forest virus

\section{Introduction}

$\mathrm{K}^{+}$currents are essential for the control of membrane responses in all neuronal compartments. The channels that mediate these currents display a high degree of functional and molecular diversity and are often localized to discrete regions of the cell (Trimmer and Rhodes, 2004). $\mathrm{K}^{+}$currents are important in neuronal dendrites, where they act to regulate dendritic excitability, modulate synaptic potentials, and repolarize backpropagating spikes (Johnston et al., 2003; Jerng et al., 2004). $\mathrm{K}^{+}$currents are also important components of somatic membranes, where they control cell excitability and shape the frequency and pattern of spike output. The intrinsic properties of the $\mathrm{Kv} 3$ class of $\mathrm{K}^{+}$channels are uniquely suited for a role in promoting spike repolarization and maintaining high frequencies of spike output (Martina et al., 1998; Wang et al., 1998; Erisir et al., 1999; Rudy and McBain, 2001; McKay and Turner, 2004; Fernandez et al., 2005).

The Kv3 family is comprised of four different genes encoding the channel proteins Kv3.1-3.4, each gene expressing several iso-

\footnotetext{
Received Aug. 30, 2005; revised 0ct. 21, 2005; accepted 0ct. 28, 2005.

This work was supported by grants from the Canadian Institutes of Health Research (CIHR) to L.M., R.W.T., and R.J.D. and a CIHR Studentship to F.R.F. R.W.T. is an Alberta Heritage Foundation for Medical Research Scientist. We gratefully acknowledge the technical assistance of Mathieu Lachance for viral preparations, William Ellis for injections and tissue preparation, and Mirna Kruskic for heterologous expression of channel constructs. We also thank Kenneth Lundstrom and Rod Bremner for providing SFV viral constructs and for advice on viral preparation.

${ }^{*} Q$.D. and A.J.R. contributed equally to this work.

Correspondence should be addressed to Robert Dunn, Department of Neurology and Neurosurgery, Montreal General Hospital, Room L7-132, 1650 Cedar Avenue, Montreal, Quebec, Canada H3G 1A4. E-mail: rob.dunn@mcgill.ca.

DOI:10.1523/JNEUROSCI.3672-05.2005

Copyright $\odot 2005$ Society for Neuroscience 0270-6474/05/2511531-11\$15.00/0
}

forms through alternative mRNA splicing (Vega-Saenz de Miera et al., 1994). These subtypes differ noticeably in their inactivation properties, with Kv3.1 and Kv3.2 channels expressing noninactivating currents and Kv3.3 and Kv3.4 expressing inactivating currents (Rudy et al., 1999b). Two of the Kv3 channel subtypes, $\mathrm{Kv} 3.1$ and Kv3.3, are often coexpressed in the same neurons (Vega-Saenz de Miera et al., 1994) but for reasons that remain to be determined. One explanation would be to provide subtypespecific signals to direct subcellular localization or regulation by second messengers. In this regard, Kv3.3 channels are distinct in exhibiting a dendritic distribution in several cell types in the cerebellum and electrosensory lateral line lobe (ELL) of the weakly electric fish Apteronotus leptorhynchus, whereas other Kv3 subtypes distribute preferentially to somatic and axonal membranes (Moreno et al., 1995; Sekirnjak et al., 1997; Rashid et al., 2001b; Martina et al., 2003). ELL pyramidal cells provide one of the most clear functional distinctions for $\mathrm{Kv} 3$ channel distribution, in that AptKv3 channels in somatic and dendritic regions differentially control the threshold for burst discharge (Rashid et al., 2001a; Noonan et al., 2003). The ELL is also subdivided into distinct sensory maps that differ in frequency-dependent processing of sensory signals that could be shaped by the expression and distribution of Kv3 channel subtypes (Shumway, 1989; Turner et al., 1996; Metzner and Juranek, 1997). Although the cellular mechanisms that control channel targeting and insertion are becoming established for the Kv1, Kv2, and Kv4 families (Misonou and Trimmer, 2004), the molecular mechanisms governing the distribution of $\mathrm{Kv} 3 \mathrm{~K}^{+}$channels are essentially unknown.

In this study, we demonstrate a distinct expression pattern for AptKv3.1 and AptKv3.3 channels across sensory maps and over 
the somadendritic axis of pyramidal cells in the ELL. We also show that $A p t \mathrm{Kv} 3.3$ channels are selectively targeted to dendritic regions by a $\mathrm{C}$-terminal targeting region that includes a potential postsynaptic density-95 (PSD-95)/Discs large/zona occludens-1 (PDZ) binding motif.

\section{Materials and Methods}

Kv3 amino acid sequences. Amino acid sequences for rat Kv3.1a,b, 3.2a-d, 3.4a,b, mouse Kv3.3a,b, and Drosophila Shaw were obtained from the GenBank/European Molecular Biology Laboratory databases. GenBank accession numbers are as follows: rKv3.1a (Y07521), rKv3.1b (M68880), rKv3.2a (A39402), rKv3.2b (M59211), rKv3.2c (M59313), rKv3.2d (S22703), mKv3.3a (Q63959), mKv3.3b (Q63959), rKv3.4a (X62841), hKv3.4b (M64676), and Shaw (M32661).

Isolation of AptKv3.1 cDNA. An Apteronotus brain cDNA library (Bottai et al., 1998) was screened with a DNA fragment corresponding to the pore and S6 domains of an Apteronotus Kv3-type $\mathrm{K}^{+}$channel gene, AptKChFr 3A (Rashid and Dunn, 1998). Kv3 cDNAs were identified by sequencing using the OpenGene Automated DNA Sequencing System (Visible Genetics, Toronto, Ontario, Canada). The sequences of overlapping clones were assembled, and the open reading frames were determined using the LASERGENE software package (DNASTAR, Madison, $\mathrm{WI})$. Among the Kv3 genes identified was an apteronotid homolog of the mammalian Kv3.1. Overlapping clones from the library spanned most of the coding region of AptKv3.1 except for the first 150 nucleotides. The remaining $5^{\prime}$ sequence was obtained by RACE PCR using a procedure described by Chenchik et al. (1996) and the translation start site for $A p t \mathrm{Kv} 3.1$ was designated as the first methionine codon downstream of an in-frame stop codon.

For in vitro expression, the full coding regions for AptKv3.1 and $A p t K v 3.3$ were isolated by reverse transcription-PCR from brain total RNA using the GeneAmp XL PCR kit (PerkinElmer, Foster City, CA). The nucleotide sequences of the PCR products were confirmed by DNA sequence analysis of both strands. The cDNAs were directionally cloned into the vector pCDNA3.1-Zeo (Invitrogen, Carlsbad, CA) using XhoI and $X b a \mathrm{I}$ restriction sites present in the PCR primers.

In situ hybridization. Apteronotus brain was fixed with $4 \%$ paraformaldehyde, and $10 \mu \mathrm{m}$ cryostat sections were probed with an ${ }^{35} \mathrm{~S}$-labeled RNA probe corresponding to part of the C-terminal and 3'-untranslated region of AptKv3.1 (nucleotides 1987-2287) and AptKv3.3 (2075-2482). After hybridization and washing, the slides were air-dried and exposed to $\mathrm{x}$-ray film for $5 \mathrm{~d}$, emulsion-dipped [1:1 dilution of NTB2 gel (Eastman Kodak, Rochester, NY) in $600 \mathrm{~mm}$ ammonium acetate], and exposed for $30 \mathrm{~d}$ at $4^{\circ} \mathrm{C}$. After developing, the slides were lightly counterstained in neutral red to permit the use of DIC microscopy.

Immunocytochemistry. A C-terminal fragment of AptKv3.1 cDNA corresponding to amino acids 520-600 was inserted into the GST fusion vector pGEX-4T-1 (Amersham Biosciences, Uppsala, Sweden). The AptKv3.1 fusion protein was expressed in the Escherichia coli strain DH5- $\alpha$ and purified as described by Frangioni and Neel (1993). Antibodies were prepared in rabbits and then depleted of glutathione $S$-transferase (GST) immunoreactivity by adsorption to GST protein bound to Affigel 10 beads (Bio-Rad, Richmond, CA). This was followed by affinity purification of the antibody by adsorption to AptKv3.1 fusion protein bound to Affigel 10 beads. The AptKv3.3 antibody has been described previously (Rashid et al., 2001a,b).

For immunohistochemistry, coronal vibratome sections $(40 \mu \mathrm{m})$ were cut from brains removed from perfused fish (Rashid et al., 2001a,b) and transferred to PBS. Sections were incubated in blocking buffer $(10 \%$ normal goat serum, $1 \%$ bovine serum albumin, and $0.2 \%$ Triton $\mathrm{X}-100$ in PBS) for $2 \mathrm{~h}$ at room temperature followed by immunolabeling in a 10 -fold dilution of blocking buffer using primary antibodies (antiAptKv3.1, $0.9 \mu \mathrm{g} / \mathrm{ml}$; anti-AptKv3.3, $0.9 \mu \mathrm{g} / \mathrm{ml}$; or mouse monoclonal anti-microtubule-associated protein (MAP) $2 \mathrm{a}, \mathrm{b}, 1.0 \mu \mathrm{g} / \mathrm{ml}$ ) at $4^{\circ} \mathrm{C}$ overnight. The sections were then washed and incubated with a 1:250 dilution of Oregon green-conjugated goat anti-rabbit IgG conjugate or rhodamine-conjugated goat anti-mouse IgG (Invitrogen, Eugene, OR) for $1 \mathrm{~h}$ at room temperature. After a series of washes in PBS, the sections were mounted onto slides and coverslipped.

Semliki Forest virus vectors for the expression of AptKv3 channels. Recombinant, replication defective Semliki Forest virus (SFV) vectors were constructed in the plasmid pScal (DiCiommo and Bremner, 1998) and modified to include two mutations in nsP2 (S259P and R650D), which reduce cellular toxicity (Lundstrom et al., 2003). These vectors are referred to as PD-Kv3. Viral stocks were prepared by cotransfection of baby hamster kidney cells with PD-Kv3 plasmids and the pSCA-Helper plasmid as described by DeCiommo and Bremner (1998). Culture supernatants containing virus were further concentrated by sedimentation through a $20 \%$ sucrose layer onto a pad of $55 \%$ sucrose. Viral stocks were dialyzed against PBS to remove sucrose and stored at $-80^{\circ} \mathrm{C}$ until use.

Expression of Kv3 channel constructs in vivo. Viral stock was pressure injected into the molecular layer of the ELL ( $~ 1 \mu$ l total) with a micropipette (20 $\mu \mathrm{m}$ tip size); injections were made at several sites to maximize the number of transfected neurons. This region contains the highly branched apical dendrites of pyramidal cells (Berman and Maler, 1999), and preliminary experiments have shown that this injection site labeled more neurons than injections into the pyramidal cell layer itself. Our sample size (fish) was as follows: seven for AptKv3.3(+19); one for AptKv3.3(+1); six for $A p t \mathrm{Kv} 3.1$; five for $A p t \mathrm{Kv} 3.1-3.3 \mathrm{CT}$; five for

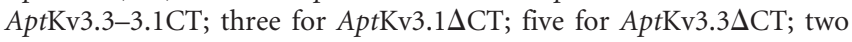
for $A p t \mathrm{Kv} 3.1-3.3 \mathrm{NT}$; one for $A p t \mathrm{Kv} 3.3-3.1 \mathrm{NT}$; four for $A p t \mathrm{Kv} 3.3 \Delta \mathrm{SIL}$. For every experimental condition, we found a minimum of 10 labeled pyramidal cells. For the conditions illustrated in Figure 5, we found $>30$ labeled pyramidal cells.

After $2 \mathrm{~d}$ of survival, the fish were deeply anesthetized and perfused with buffered paraformaldehyde (4\%); preliminary experiments have shown that labeling intensity is maximal by $2-3 \mathrm{~d}$. Frozen sections $(80$ $\mu \mathrm{m}$ ) were then cut and mounted. All protocols were approved by the University of Ottawa Animal Care Committee. A Zeiss (Thornwood, NY) LSM 410 confocal microscope was used to study the expression of transfected Kv3 construct. Confocal stacks were examined and flattened using NIH ImageJ. Adobe Photoshop (Adobe Systems, San Jose, CA) was used to make minor adjustments to image contrast.

\section{Results}

\section{The Apteronotus Kv3.1 potassium channel}

Electrophysiological studies have established that the Kv3 class of potassium channels contribute to high-frequency spike output and the generation of spike bursts in ELL pyramidal cells (Rashid et al., 2001a; Turner et al., 2002; Fernandez et al., 2005). Kv3 channels repolarize sodium spikes at both the somatic and apical dendritic level but have opposing actions on the threshold for burst discharge by modulating a dendrosomatic current flow that governs somatic excitability (Rashid et al., 2001a; Noonan et al., 2003). To characterize the $\mathrm{K}^{+}$channel subtypes that underlie somatic and dendritic currents, we performed molecular analysis of the Kv3 potassium channels in ELL pyramidal neurons.

Mammals express four Kv3 genes (Kv3.1-3.4), each of which can be spliced in the C-terminal region to yield a series of alternatively spliced isoforms (for review, see Vega-Saenz de Miera et al., 1994). Our previous studies have demonstrated that the apteronotid ortholog of the mammalian Kv3.3 potassium channel, $A p t \mathrm{Kv} 3.3$, is expressed at high levels in both the somas and dendrites of ELL pyramidal cells (Rashid et al., 2001a). In addition, preliminary in situ hybridization studies indicated that a second Kv3 subtype, AptKv3.1, was also expressed in these neurons. To facilitate studies of the relative roles for these two Kv3 subtypes, we isolated the AptKv3.1 cDNA and compared the properties and expression of both $\mathrm{Kv} 3$ subtypes in this system.

A comparison of the deduced amino acid sequence of AptKv3.1 with the complete rodent $\mathrm{Kv} 3$ gene family indicated that $A p t \mathrm{Kv} 3.1$ is most similar to the rat splice isoforms $\mathrm{rKv} 3.1 \mathrm{a}$ and $\mathrm{rKv} 3.1 \mathrm{~b}$ (Fig. $1 A, B$ ). AptKv3.1 is further identified as the 
A

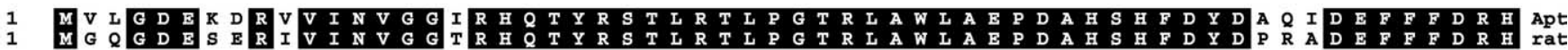

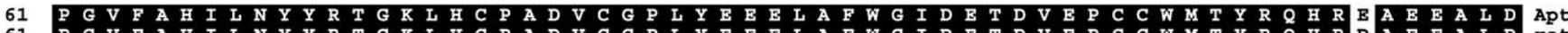

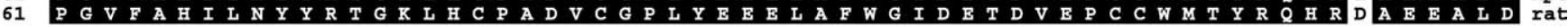

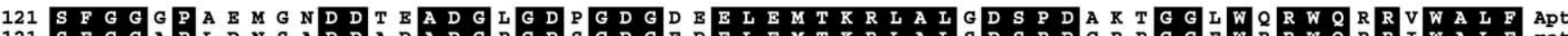
121 S F G G S1

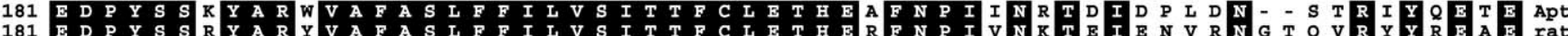
S2 S3

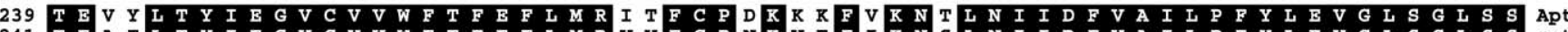

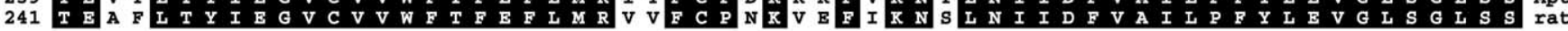

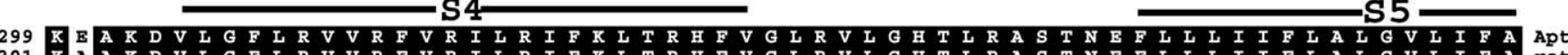

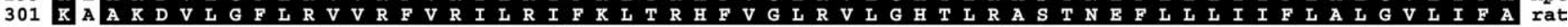

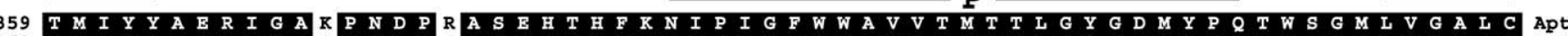
361 T M I Y Y A E R I G A Q P N D P S A S E H T H F K N I P I G F W W A V V T M T T L G Y G D M Y P Q T W S G M L V G A L C Tat $S 6$

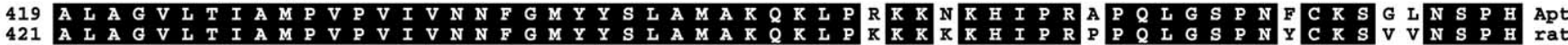

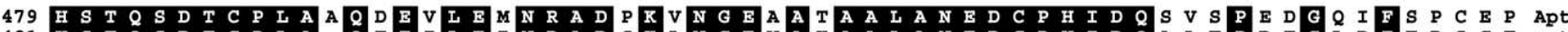
481 H S T C C S D T C P L A

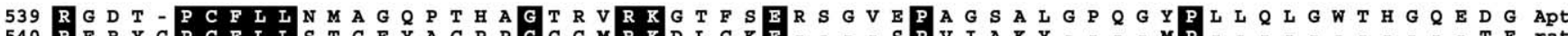

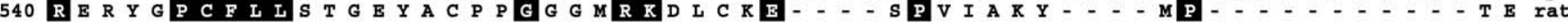

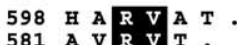

$\mathbf{B}$

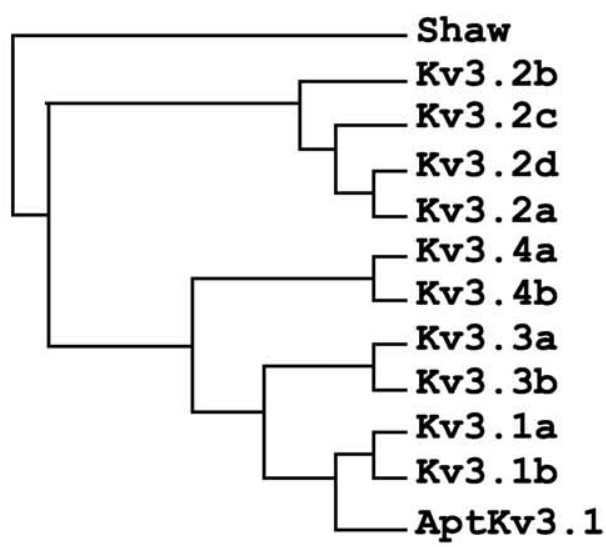

Kv3.1
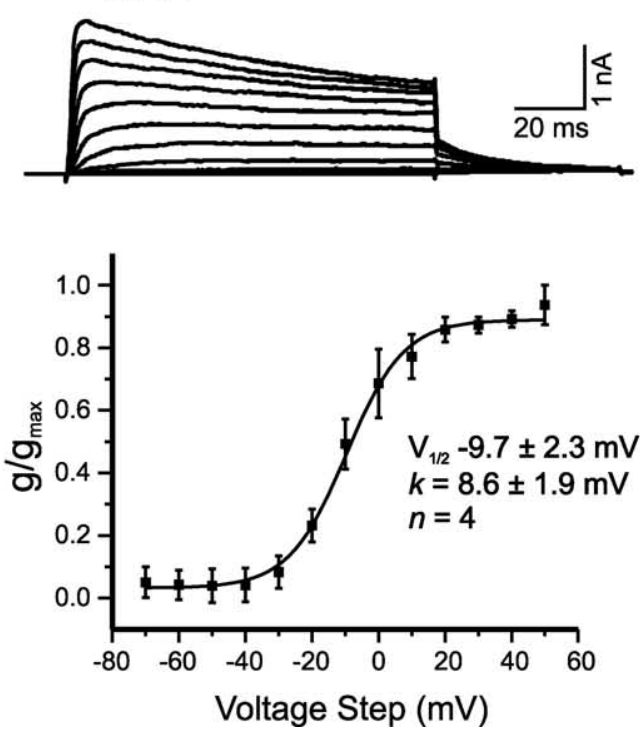

Figure 1. Characterization of the AptKv3.1 $\mathrm{K}^{+}$channel. $A$, Alignment of the amino acid sequences for AptKv3.1 with the rat Kv3.1b channel. The six predicted transmembrane segments (S1-S6) and the predicted ion pore (P) are indicated by solid lines above the sequence. Amino acid identities are outlined in black. $\boldsymbol{B}$, Phylogenetic comparison of $A$ ptKv3.1 to members of the mammalian Kv3 family. The sequence used for comparison is rat Kv3, except for human Kv3.4b. Analysis by the parsimony method was performed using the PROTPARS program in the Phylogeny Inference Package (Golding and Felsenstein, 1990). The Drosophila Shaw $\mathrm{K}^{+}$channel was used as the outgroup. C, Outside-out voltage-clamp recordings of AptKv3.1 current expressed in CHO cells demonstrate an outwardly rectifying and high-threshold potassium channel. The command pulses were stepped in $10 \mathrm{mV}$ increments (100 ms) from a holding potential of -70 to $50 \mathrm{mV}$ and stepped back to $-40 \mathrm{mV}$.

ortholog of rKv3.1b because the C-terminal segment of AptKv3.1 (amino acids 501-603) is much more similar to the $\mathrm{C}$ terminus of rKv3.1b than to the very short 10 residue C-terminal segment of rKv3.1a (Vega-Saenz de Miera et al., 1994). The fish and rat channels share very high-sequence identities throughout, with most of the divergence limited to a 25 amino acid segment in the $\mathrm{N}$ terminus proximal to the first transmembrane segment and the last 81 residues of the $\mathrm{C}$ terminus (Fig. $1 A$ ). High levels of sequence similarity between the AptKv3.3 channel and mammalian Kv3.3 were also shown previously (Rashid et al., 2001a), suggesting that 
the functional properties that differentiate the two Kv3 subtypes have been conserved in both teleost and mammalian lineages. Expression of AptKv3.1 channel cDNA in Chinese hamster ovary $(\mathrm{CHO})$ cells revealed typical outward rectifying currents with fast activation and deactivation kinetics in the outside-out configuration, and a $V_{1 / 2}$ for activation of $-9.7 \pm$ $2.3 \mathrm{mV}(k=8.6 \pm 1.9 \mathrm{mV})$ (Fig. $1 C)$. AptKv3.1 channels were also highly sensitive to tetraethylammonium $(<1 \mathrm{~mm})$ and single-channel conductance in the on-cell mode was in the order of $35 \mathrm{pS}$ (data not shown), similar to that observed for AptKv3.3 channels (Fernandez et al., 2003). Thus, the AptKv3.1 channel shares a similar set of characteristics to its mammalian counterpart (Coetzee et al., 1999), indicating a high degree of preservation of function in this potassium channel family. Pyramidal neurons of the ELL express two Kv3 channels, with a gradient of $A p t \mathrm{Kv} 3.1$ across the somatotopic electrosensory maps.

In situ hybridization studies were performed to compare the expression of the two Kv3 channel mRNAs in the neurons of the ELL. In coronal sections through the hindbrain, the ELL can be seen in the ventral aspect as well as a defined laminar structure along the mediolateral axis, with a layer of pyramidal cells just dorsal to a layer of granular cell interneurons (Fig. 2A). On the dorsal aspect lies the caudal lobe of the cerebellum, the eminentia granularis posterior (EGp), from which granule neurons send parallel fibers that synapse on the apical dendrites of pyramidal neurons in the molecular layer of the ELL (Berman and Maler, 1999). Hindbrain sections in this orientation include the four topographic maps or segments of the ELL: medial segment (MS), centromedial segment (CMS), centrolateral segment (CLS), and lateral segment (LS). Three of these segments (CMS, CLS and LS) receive afferent inputs from tuberous electroreceptors, whereas the fourth (MS) receives inputs from ampullary electroreceptors (Carr and Maler, 1986).

The patterns of AptKv3.1 and AptKv3.3 mRNA expression in the ELL are shown in Figure $2 B$. As described previously (Rashid et al., 2001a), AptKv3.3 mRNA is expressed prominently in both the pyramidal and granule neurons of the ELL but only in a few cells of the overlying EGp. In contrast, the Kv3.1 mRNA is at high levels in the granule cells of the EGp, at moderate levels in ELL pyramidal neurons and only low levels in the granule neurons of the ELL proper. A strong signal for $A p t \mathrm{Kv} 3.1$ was also observed in the granule neurons of the corpus cerebelli $(\mathrm{CCb})$ and in the eminentia granularis medialis (EGm), a proliferative zone that contains EGp granule cell precursors (Zupanc and Horschke, 1995). No signal was observed when hybridizing with the corresponding sense probes (data not shown).

Examination of tissue sections indicated an apparent gradient of expression for AptKv3.1 mRNA across the different segments of the ELL (Fig. $2 B$ ). Expression levels appeared to be highest in the medial and lateral segments and lowest in the centromedial segment. The gradient of mRNA expression in the pyramidal neurons of the ELL suggested that the levels of channel protein should also vary between segments. As shown in Figure $2 C$, immunohistochemical analysis of $A p t \mathrm{Kv} 3.1$ channel protein also indicated that Kv3.1 channel protein was more abundant in the lateral and medial segments, in agreement with the in situ hybridization data. The gradient of $A p t \mathrm{Kv} 3.1$ gene expression contrasts with the uniform level of $A p t K v 3.3$ gene expression in these same neurons.

\section{$A p t \mathrm{Kv} 3.1$ protein is restricted to the soma and proximal dendrites of ELL pyramidal cells}

We have shown previously that AptKv3.3 channels are present throughout the full extent of the long apical dendrites of the ELL pyramidal neurons (Rashid et al., 2001a). To determine the distribution of $A p t \mathrm{Kv} 3.1$ in pyramidal cells, we prepared an antibody against the C-terminal domain of AptKv3.1 ( $\alpha$-AptKv3.1) and mapped the distribution of $A p t \mathrm{Kv} 3.1$ channel protein in pyramidal neurons. The ability of the antibody to recognize AptKv3.1 was confirmed by Western blot analysis of Apteronotus brain proteins and by immunohistochemical staining of AptKv3.1-transfected CHO cells (data not shown).

A comparison of the distributions of the two Kv3 channel subtypes within the ELL is shown in Figure 3. Intense immunostaining for AptKv3.1 was detected in pyramidal cell somata and within the initial portion of pyramidal cell apical dendrites (Fig. $3 A$ ). The intensity of $A p t \mathrm{Kv} 3.1$ labeling dissipated beyond visual detection within a maximal distance of $200 \mu \mathrm{m}$ into the molecular layer and clearly did not extend the full length of apical dendrites $(600-800 \mu \mathrm{m})$. In contrast, the distribution of the AptKv3.3 immunolabel extended throughout the apical dendrites, including the very distal segments up to $800 \mu \mathrm{m}$ from the soma (Fig. $3 B$ ). The diffuse, punctate staining that could be observed for $A p t \mathrm{Kv} 3.1$ throughout the molecular layer (Fig. $3 A$ ) is attributable to AptKv3.1 in axonal and presynaptic structures (discussed below). Pyramidal neurons project axons densely to layers 5 and 7 of the torus semicircularis, a midbrain structure similar to mammalian inferior colliculus (Maler et al., 1982). We failed to detect immunohistochemical signals for either AptKv3.1 or AptKv3.3 in these regions (data not shown), which suggests that neither of these channels is targeted to axonal domains by ELL pyramidal neurons.

The difference in the distributions of $A p t \mathrm{Kv} 3.1$ and $A p t \mathrm{Kv} 3.3$ in apical dendrites is seen better under higher magnification of sections costained with antibodies for either AptKv3.1 or AptKv3.3 and an antibody for MAP-2a,b. At a distance $\sim 150 \mu \mathrm{m}$ away from the soma, an overlapping distribution of MAP-2 and AptKv3.3 immunolabel is clearly shown (Fig. 3C). In a corresponding area colabeled with $\alpha$-MAP-2 and $\alpha$-AptKv3.1, small 1-2 $\mu \mathrm{m}$ patches of $A p t \mathrm{Kv} 3.1$ immunolabel were observed, which did not correspond with the MAP-2 stain characteristic of pyramidal cell dendrites (Fig. 3D). Granule cells of the EGp, which express high levels of AptKv3.1 mRNA (Fig. 2A), provide descending projections to the ELL and are likely responsible for the extra-dendritic $A p t \mathrm{Kv} 3.1$ protein observed in the molecular layer (Maler et al., 1981). This interpretation is consistent with findings in other species in which Kv3.1 has been localized to cerebellar parallel fibers and other axonal membranes (Devaux et al., 2003; Matsukawa et al., 2003).

To further characterize the distributions of these channels in the molecular layer, we compared the staining with that of synaptic vesicle protein 2 (SV2), a presynaptic marker. SV2 antibody labeled numerous synaptic structures throughout the molecular layer (Fig. 3Eii,Fii). The Sv2-labeled structures were located adjacent to the AptKv3.3-labeled dendrites (Fig. 3E). When compared with AptKv3.1 staining, the SV2-labeled presynaptic structures showed substantial overlap with a subset of the AptKv3.1 puncta (Fig. $3 F$ ). This result is fully consistent with the localization of AptKv3.1 to the axons and some of the presynaptic structures of the parallel fibers that originate in the EGp. In contrast, the SV2 staining appeared to outline strands of Kv3.3 staining, consistent with a presynaptic localization of SV2 apposed to the dendritic shafts. We conclude that in pyramidal neurons, 

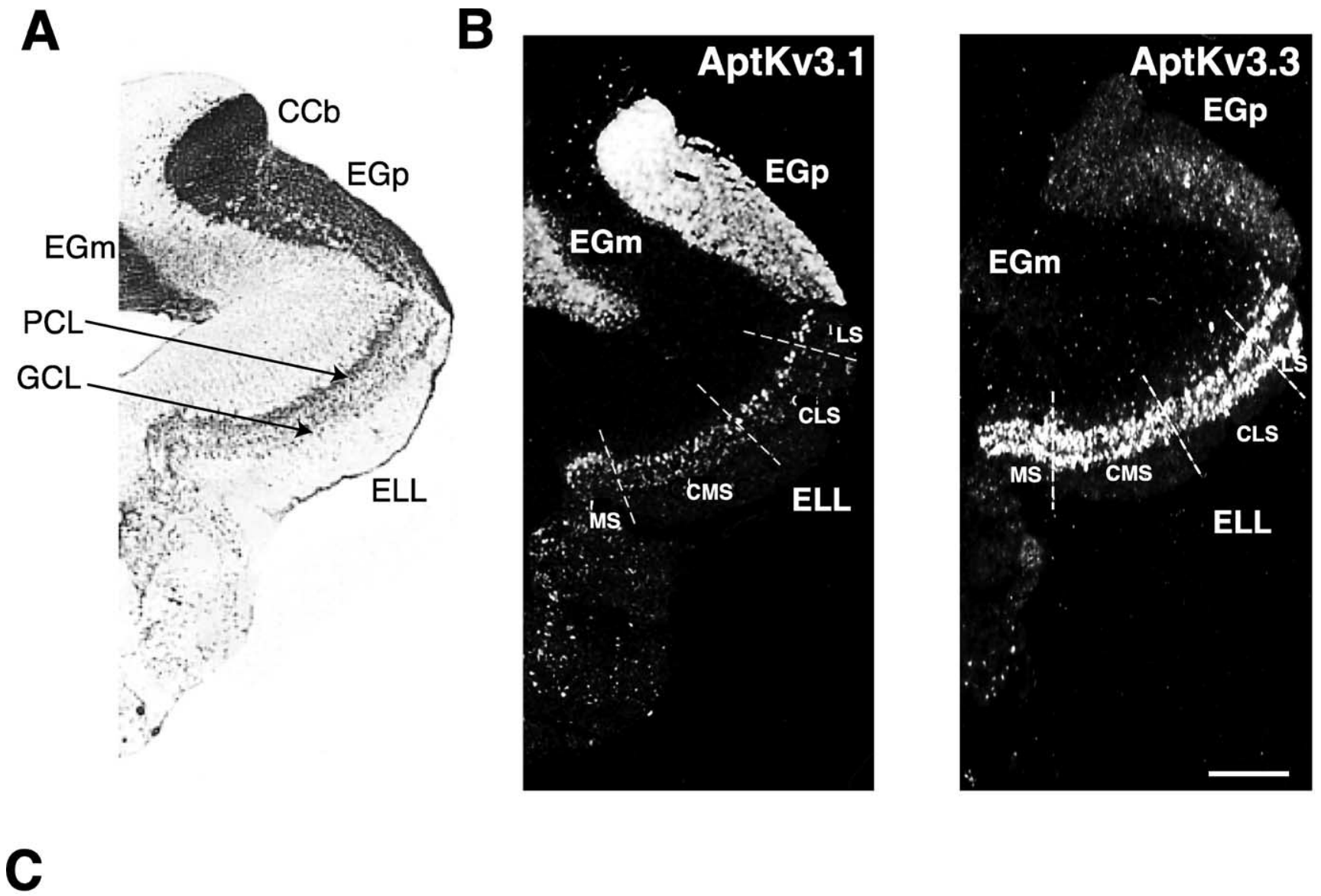

MS

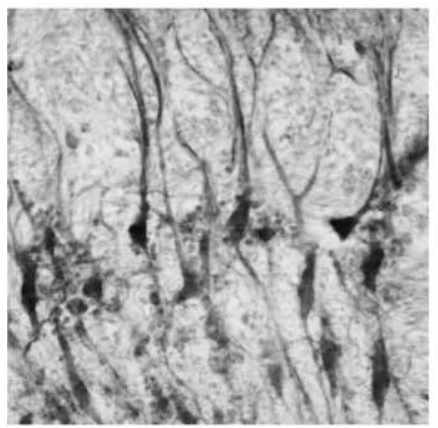

CMS

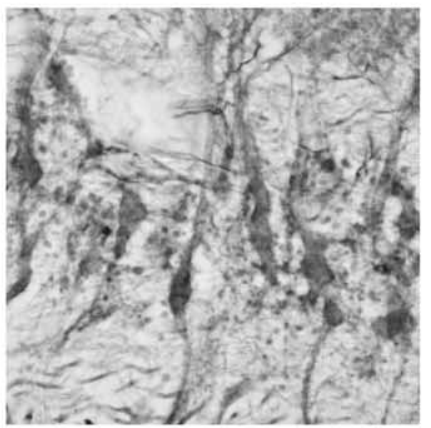

CLS

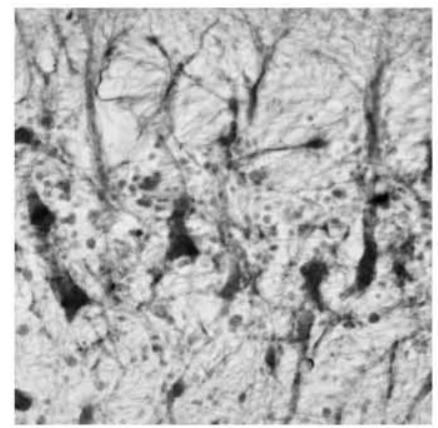

LS

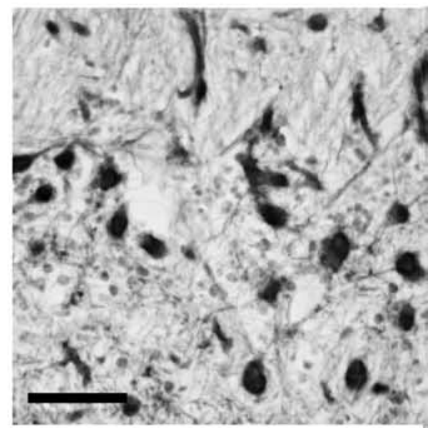

Figure 2. AptKv3.1 and AptKv3.3 are coexpressed in the pyramidal neurons of the ELL. $A$, Transverse section of the Apteronotus hindbrain stained with cresyl violet. The two prominent cell layers in the ELL, pyramidal cell layer (PCL), and granule cell layer (GCL), are indicated. $\boldsymbol{B}$, In situ hybridization analysis of AptKv3 mRNAs in the hindbrain neurons. Dashed lines indicate the boundaries between different segments of the ELL. AptKv3.1 mRNA is expressed most strongly in granule neurons of the cerebellum (CCb and EGp) and in the pyramidal neurons of the ELL. Granule neurons of the ELL exhibit low levels of signal. In the pyramidal neurons, the intensity of the signal varies among the segments such that LS/MS $>C L S>C M S$. AptKv3.3 mRNA is at high levels in pyramidal and granule neurons of all segments of the ELL. Expression of AptKv3.3 is present in only a subset of neurons in the CCb and EGp and only at very light levels in granule neurons of the cerebellum. $C$, AptKv3.1 channel protein appears to be expressed in a gradient, with LS/MS >CLS >CMS. ELL sections were stained with $\alpha$-AptKv3.1 antibody and visualized using HRP histochemistry. Antibody labeling is restricted to the somatic and proximal dendrites. Scale bar: $\boldsymbol{B}, 300 \mu \mathrm{m} ; \boldsymbol{C}, 25 \mu \mathrm{m}$.

AptKv3.1 is mostly, if not completely, limited to the proximal 50-100 $\mu \mathrm{m}$ of the apical dendrites.

\section{Apt Kv3 channel constructs for SFV-directed gene expression} The mechanisms responsible for a selective distribution of $A p t K v 3.1$ and $A p t K v 3.3$ channels must involve targeting signals that distinguish between these two closely related channel subtypes. The only accessory subunits shown to associate with Kv3 channels are the Mink-related peptides, which can modulate channel kinetics (Lewis et al., 2004) but have not been shown to regulate subcellular distributions in neurons. In Kv3.2 channels, a C-terminal sequence has been shown to direct insertion into the apical pole of Madin-Darby canine kidney cells (Ponce et al., 1997), although the targeting sequence and its relationship to neuronal channel targeting has not been examined. Given that the majority of sequence differences between $A p t \mathrm{Kv} 3.1$ and AptKv3.3 are located in the $\mathrm{N}$-terminal and C-terminal intracellular segments, we reasoned that these segments could provide the signals required to target the distribution of each subtype. As a first step in the analysis of the targeting mechanisms, we devel- 
oped methods to express recombinant AptKv3 channels in ELL pyramidal neurons in vivo.

Vectors based on replication-defective forms of the two closely related alphaviruses, Semiliki Forest virus and the Sindbis virus, have been developed for gene delivery to a variety of tissues, including the nervous system (D'Apuzzo et al., 2001; Ehrengruber et al., 2001; Lundstrom and Ehrengruber, 2003). These vectors are attractive candidates for gene delivery to the teleost nervous system, because they display a wide species host range and, in many cases, exhibit cell specificity for neurons (Frolov et al., 1996). Recent developments in these vectors have included the introduction of mutations, which greatly reduce cellular toxicity and enhance gene expression (Lundstrom et al., 2001). To determine whether SFV-based vectors would program gene expression in the ELL, we created several AptKv3.1 and AptKv3.3 channel constructs tagged with enhanced green fluorescent protein (EGFP). The sequence encoding the EGFP protein was joined to the cDNAs of $A p t \mathrm{Kv} 3.1$ and $A p t \mathrm{Kv} 3.3$ such that the fusion proteins had EGFP at their $\mathrm{N}$ termini. For AptKv3.1, the EGFP sequence was joined to the methionine at position 1 such that the complete sequence of AptKv3.1 was present in the encoded fusion protein. For $A p t \mathrm{Kv} 3.3$, the EGFP was fused at either of two positions. In one case, the EGFP was positioned directly in front of the initiator methionine, and in the second the EGFP was located at position +19 and replaced the inactivation particle encoded by amino acids 1-18. For the mutational analysis of AptKv3.3 targeting, the fusion at position +19 was used in all cases.

To confirm that selective sequence deletion and GFP fusion did not disrupt the structure and assembly of the proteins, cDNAs encoding each of the constructs were transfected into $\mathrm{CHO}$ cells, and voltage-activated outward currents were recorded (supplemental Fig. S1, available at www.jneurosci.org as supplemental material). The full range of deletions and substitutions tested are described in detail below and provided in schematic format in Figure 4. Supplemental Figure S1 (available at www.jneurosci.org as supplemental material) also compares the currents expressed in $\mathrm{CHO}$ cells between unmodified AptKv3.1 and AptKv3.3 modified constructs, each of which contains the EGFP protein fused at the $\mathrm{N}$ terminus. All recombinant proteins yielded voltage-gated potassium currents with amplitudes, kinetics, and voltage dependencies generally
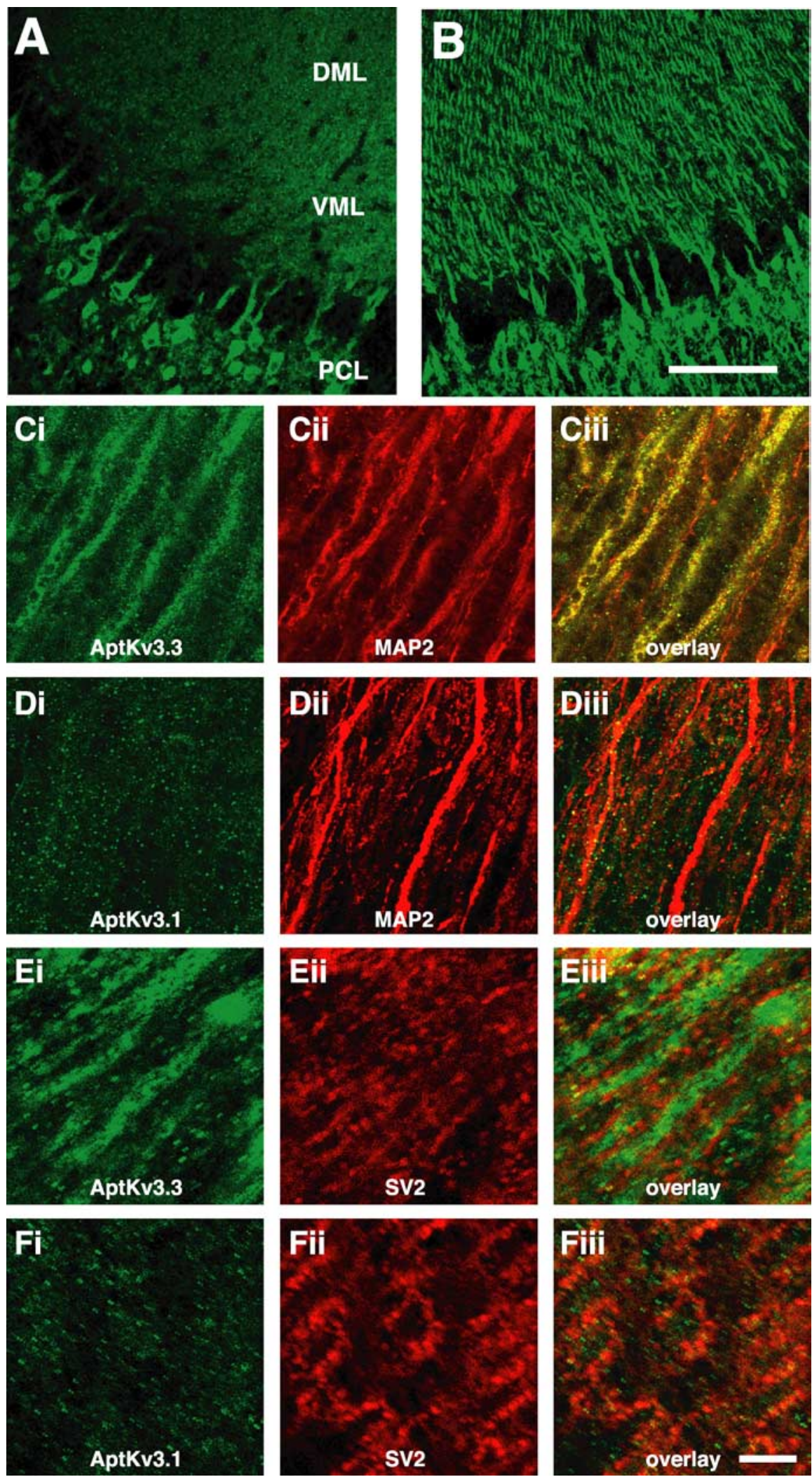

Figure 3. AptKv3.3, but not AptKv3.1, is localized to the distal apical dendrites of pyramidal neurons in the ELL.A, B, ELL pyramidal cell layer and overlying molecular layer reacted with antibody to AptKv3.1 (A) and AptKv3.3 (B). The immunolabel for AptKv3.3 but not AptKv3.1 in the dendrites of the VML and DML is shown. Strong signals for both are observed in pyramidal cell somata. PCL, Pyramidal cell layer; DML, dorsal molecular layer; VML, ventral molecular layer. $\mathbf{C}-\boldsymbol{F}$, All images are of the dorsal molecular layer $\sim 300-500 \mu \mathrm{m}$ above the pyramidal cell layer. Sections stained with antibodies to AptKv3.1, AptKv3.3, MAP2, and SV2 are shown. Apical dendrites as identified by MAP2 (red) are strongly labeled for AptKv3.3 (green) in (but are not labeled for AptKv3.1 (green) in D. In E, AptKv3.3 (green) staining in the dendritic shaft is outlined by the immunolabel for the presynaptic vesicle marker SV2 (red). In $F$, the immunolabel for AptKv3.1 shows partial overlap with the SV2 label (red). Scale bars: (in $B) A, B, 100 \mu \mathrm{m}$; (in Fiii) $C-F, 25 \mu \mathrm{m}$. 


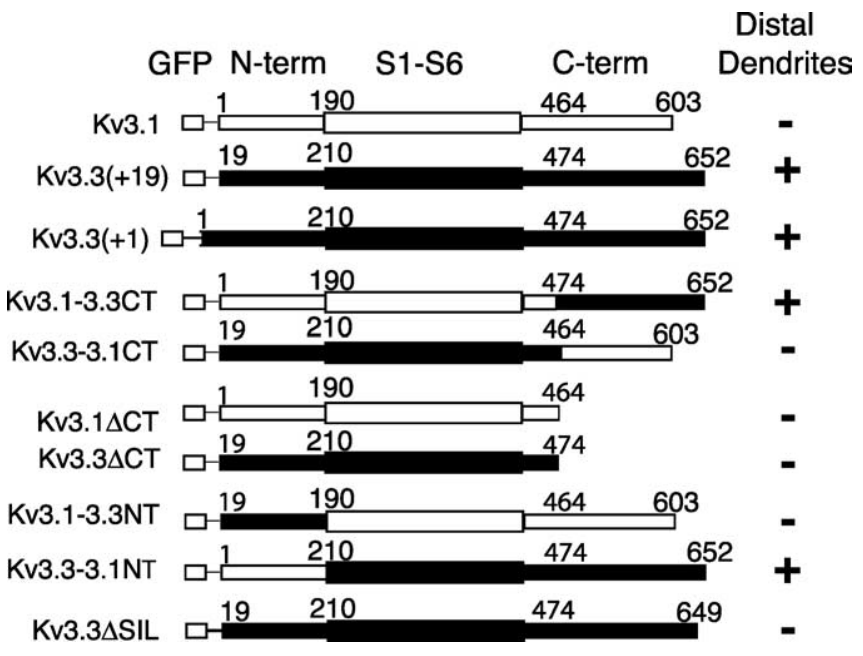

Figure 4. Schematic representation of the various GFP-AptKv3 channel proteins, including the recombinant chimeric or deletion proteins. Amino acid positions are indicated above each construct. For segment switches, CT and NT indicate C-terminal (C-term) and N-terminal (Nterm) segments. $\Delta C T$ indicates the truncation of the C-terminal region. $\Delta$ SIL indicates the removal of the SIL sequence from the $C$ terminus. The amino acid positions of EGFP fusion to AptKv3.3 are indicated by $(+1)$ and $(+19)$. The presence $(+)$ or absence $(-)$ of GFP fluorescence $300-500 \mu \mathrm{m}$ above the pyramidal cell layer is indicated on the right.

similar to unmodified AptKv3.1 and AptKv3.3 channels expressed in the same cells (supplemental Fig. S1, available at www. jneurosci.org as supplemental material). As expected, EGFPAptKv3.3 constructs failed to show the inactivation properties of unmodified AptKv3.3 resulting from replacement of the inactivation ball of the $\mathrm{N}$ terminus. In each case, currents were first activated at approximately -40 to $-30 \mathrm{mV}$, with a time peak within $10 \mathrm{~ms}$, as found for unmodified channels. Thus, all of the recombinant channels yielded voltage-gated currents in $\mathrm{CHO}$ cells, indicating that channel modifications did not hinder channel folding, translocation, or insertion in the membrane, establishing that EGFP fluorescence of recombinant channels can reflect the insertion of functional channels in the membrane.

SFV vectors direct gene expression to ELL pyramidal neurons To test whether SFV-based vectors would program gene expression in the ELL, we first injected a recombinant SFV virus expressing only EGFP-F, the farnsylated derivative of EGFP (Jiang and Hunter, 1998), into the dorsal molecular layer of the ELL in the live animal under stereotaxic control (Maler et al., 1991). After $2 \mathrm{~d}$ of survival, sections of the hindbrain were examined for expression of the recombinant channel protein determined by fluorescence microscopy. We found the viral expression vector successfully programmed EGFP-F gene expression in large numbers of neurons in these sections. Moreover, EGFP-F expression was limited to neurons, with no evidence for glial cell expression. Most of the labeled cells were pyramidal neurons localized in the ELL pyramidal cell layer, indicating that injection of the virus into the dorsal molecular layer resulted in efficient adsorption of the virus by pyramidal neuron dendritic processes that project into this region. In addition, we did not observe GFP fluorescence in granule cells of the overlying cerebellar EGp, indicating that the virus was not taken up by the prominent parallel fibers that project through this region.

In ELL pyramidal neurons, the EGFP-F label was distributed throughout the somatic and dendritic compartments. Fluorescence was observed to extend to the most dorsal extent of the molecular layer, which corresponds to the distal region of pyramidal cell apical dendrites (Fig. $5 A$, black arrows). The label also extended ventrally throughout the basal dendrite, including the basilar bush that receives input from electroreceptor afferents (Berman and Maler, 1999) (Fig. 5A, white arrow). In addition, all known classes of pyramidal cells were labeled (basilar and nonbasilar, superficial to deep) (Berman and Maler, 1999), indicating that the virus did not selectively label a subset of pyramidal cells. Viral delivery of EGFP-F for up to 1 week did not result in observable necrosis or tissue disruption. Our results thus demonstrate that the SFV vectors are an effective means to deliver recombinant gene expression to the pyramidal neurons of the ELL, and that an EGFP-F tag does not hinder protein distribution over the cell axis.

SFV vectors expressing EGFP-AptKv3.1 and EGFP-AptKv3.3 were then injected into the ELL and the expression of the channels determined after $2 \mathrm{~d}$. As shown in Figure $5 B$, recombinant EGFP-AptKv3.3 was distributed throughout the full apical and basilar dendritic trees. In the apical dendrites, the fluorescent signal extended as far as $800 \mu \mathrm{m}$ to the most dorsal region of the ELL molecular layer. In contrast, $A p t \mathrm{Kv} 3.1$ was restricted to the cell body and only the more proximal apical dendritic segments of pyramidal neurons (Fig. $5 C$ ). These results are in agreement with the immunohistochemical localization of these channels and demonstrate that the mechanisms responsible for the targeting of the two Kv3 channels are fully active on the virally expressed channel constructs.

\section{Dendritic targeting of AptKv3.3 is dependent on the C-terminal segment}

Examination of the two Kv3 channel subtypes indicated that the majority of sequence differences occur within the $\mathrm{N}$-terminal and C-terminal regions, which suggested that the sequences responsible for differential targeting are likely to be located in one or both of these regions. To examine this possibility, viral expression constructs were prepared in which either the $\mathrm{N}$ - or C-terminal regions of the two channel proteins were substituted with analogous sequences from the other channel. These constructs are shown in schematic form in Figure $4 A$.

The expression of either the AptKv3.3(+1) or the AptKv3.3(+19) fusion proteins resulted in channel distribution throughout the full dendritic axis of pyramidal cells (Figs. 4, 5B), which indicated that the $\mathrm{N}$-terminal inactivation particle encoded by residues $1-18$ is not required for dendritic targeting of the Kv3.3 protein. However, we found that channel targeting could be completely reversed by switching the $\mathrm{C}$ termini. Substitution of the $\mathrm{C}$-terminal region of $A p t \mathrm{Kv} 3.3$ with the $\mathrm{C}$ terminus of $A p t \mathrm{Kv} 3.1$ restricted AptKv3.3 channel distribution to the soma and proximal dendritic region, as normally found for the AptKv3.1 channel (Fig. 5D). In contrast, fusion of the C-terminal sequence of $A p t \mathrm{Kv} 3.3$ to the $A p t \mathrm{Kv} 3.1$ channel protein efficiently directed $A p t \mathrm{Kv} 3.1$ channels out from the soma and over the full extent of the apical and basilar dendrites (Fig. 5E). For the AptKv3.3-3.1CT (Fig. 5D), there did appear to be a small amount of fluorescent label in the dorsal regions of the molecular layer. This weak targeting phenotype is likely the result of the formation of channel tetramers containing one or more subunits of the endogenous $A p t \mathrm{Kv} 3.3$ channel and the expressed construct. However, comparison of Figure 5, $B$ and $D$, clearly demonstrates that the C-terminal tail sequence of $A p t \mathrm{Kv} 3.3$ is required for full targeting of the channel to distal domains of the apical dendrite. It is possible that the C-terminal segment of AptKv3.1 acts to restrict Kv3 channels to the soma. However, expression of either 

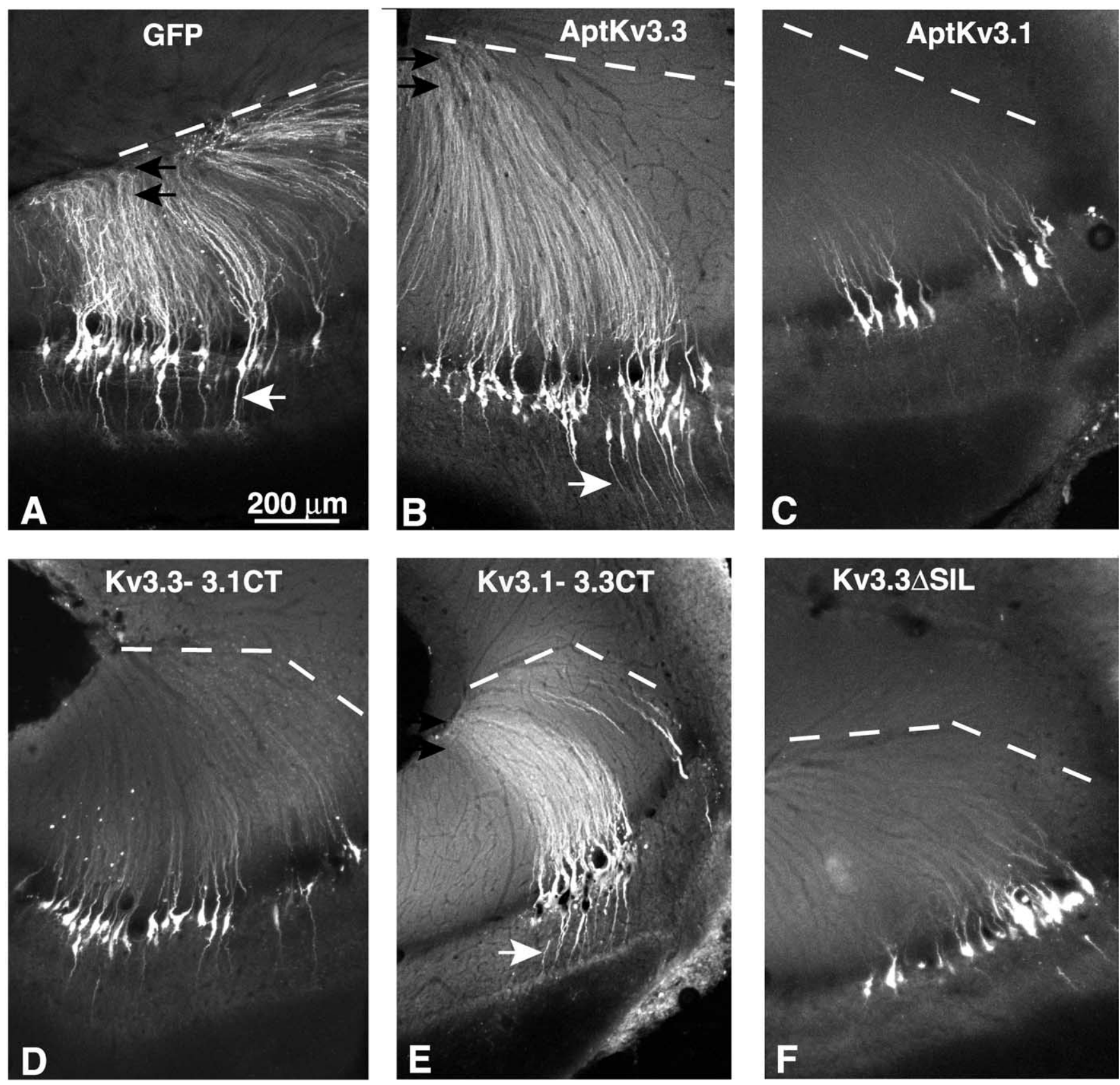

Figure 5. The C-terminal segment of AptKv3.3 is required for channel localization to distal dendrites of pyramidal neurons. GFP fluorescence was analyzed in $80 \mu \mathrm{m}$ sections of ELL from fish injected with recombinant SFV viral particles in the dorsal molecular layer of ELL under stereotaxic control. Apical dendrites extend upward to the most dorsal edge of the ELL, shown as a dashed line. $A$, Viral expression of EGFP-F exclusively labels pyramidal neurons. The fluorescent signal extends dorsally to the full extent of the apical dendrites (black arrows) and ventrally to the basilar dendrite (white arrow). B, GFP-AptKv3.3(+19) channels localize throughout the full extent of the apical (black arrows) and the basilar (white arrow) dendrites. C, GFP-AptKv3.1 channels are restricted to the somas and proximal segments of the apical dendrites. D, Replacement of the C-terminal segment of GFP-AptKv3.3 with the corresponding segment from AptKv3.1 inhibits distal dendritic localization. $\boldsymbol{E}$, Replacement of the C-terminal segment of GFP-Kv3.1 with the corresponding segment for AptKv3.3 promotes localization to the apical (black arrows) and basilar (white arrow) dendrites. $\boldsymbol{F}$, Deletion of the C-terminal tripeptide from GFP-AptKv3.3 inhibits localization to distal apical dendrites.

AptKv3.1 or AptKv3.3 channels, with truncations that leave 30 nearly identical residues (only 2 of the 30 residues differ between the two channels in this segment) on the C-terminal side of S6, resulted in channels restricted to the somatic compartments in both cases (supplemental Fig. S2A, S2B, available at www. jneurosci.org as supplemental material). We conclude that the AptKv3.3 C-terminal intracellular tail segment contains a sequence that is required for the dendritic delivery of Kv3 channels. In comparison, exchanging the $\mathrm{N}$ termini did not affect the targeting phenotype of either channel subtype (supplemental Fig.
$\mathrm{S} 2 C$, S2D, available at www.jneurosci.org as supplemental material).

The amino acid sequence of the $\mathrm{C}$ terminus of AptKv3.3 provided a clue to the possible mechanism for the dendritic targeting, because it includes the amino acid sequence PIPSIL, which is consistent with the consensus sequence for a type I interaction with a PDZ protein-protein interaction motif (Sheng and Sala, 2001). In comparison, no such sequence was present in the AptKv3.1 C-terminal region, identifying a difference in C-terminal sequence potentially important to AptKv3.3 target- 
ing. To test this hypothesis, a viral vector expressing a derivative of $A p t \mathrm{Kv} 3.3$ with the C-terminal amino acids SIL removed was injected into the ELL. As shown in Figure $5 F$, removal of only three residues from the $\mathrm{C}$ terminus of $A p t \mathrm{Kv} 3.3$ completely inhibited dendritic targeting when expressed in pyramidal neurons. This result indicates that the mechanism that targets AptKv3.3 to the distal dendrites requires a C-terminal sequence that is likely to involve interaction with a protein that contains a $\mathrm{PDZ}$ protein interaction motif.

\section{Discussion}

The present study establishes that AptKv3.1 channels exhibit a differential expression across multiple maps of a sensory nucleus that is restricted to the somatic region of the principal output neuron. AptKv3.3 channels have an additional widespread distribution over dendritic regions that is mediated by a specific targeting sequence on the $\mathrm{C}$ terminus. The resulting differences in subcellular localization of Kv3 channel subtypes have important implications for the role of these channels in regulating somadendritic interactions that affect sensory processing across multiple sensory maps.

Our results indicate that the AptKv3.1 channel gene is expressed in a graded manner across the four segments of the ELL, with higher levels in the lateral and medial segments. Both the in situ hybridization and immunohistochemical studies show that AptKv3.1 is expressed at higher levels in pyramidal neurons of the LS, the segment preferentially responsive to high-frequency electrosensory input, than in CMS or CLS (Shumway, 1989; Turner et al., 1996; Metzner and Juranek, 1997). We note that this apparent gradient of $A p t \mathrm{Kv} 3.1$ is analogous to the gradients of Kv3.1 gene expression observed in rodent and avian auditory nuclei ( $\mathrm{Li}$ et al., 2001; Parameshwaran et al., 2001). For example, neurons in the medial nucleus of the trapezoid body express Kv3.1 in a gradient with higher levels in the high-frequency domains of the tonotopic organization ( $\mathrm{Li}$ et al., 2001).

\section{Dendritic AptKv3.3 targeting is directed by a C-terminal motif}

Both immunohistochemical localization and recombinant channel targeting experiments demonstrate that AptKv3.1 channels are restricted to the somatic and proximal regions of the apical dendrites, but that $A p t \mathrm{Kv} 3.3$ is distributed to all regions of the apical dendrites of pyramidal cells. Such a selective subcellular distribution of two closely related channels suggested the presence of specific targeting motifs on one or both of these proteins. Because the core regions spanning the six transmembrane segments of these two proteins are highly similar (81\% amino acid identity), it was likely that the targeting signals would be located in the $\mathrm{N}$ - and/or C-terminal intracellular segments of the channel. To test this idea, we used in vivo injection of recombinant SFV viral vectors to achieve robust expression of GFP-tagged intact or recombinant channel constructs to identify the location of the targeting sequence(s). The GFP staining that we observed in these studies is likely to result from the combination of channels localized to both the cell surface and the intracellular transport vesicles. The fact that $A p t \mathrm{Kv} 3.1$ does not appear in the intracellular compartments of the distal dendrites suggests that targeting of $\mathrm{Kv} 3$ channels is mediated by directed vesicle delivery rather than by selective retention mechanisms. Directed transport has also been suggested for the dendritic targeting of Kv.4.2 channels in cortical pyramidal neurons (Rivera et al., 2003) and for transferrin receptors expressed in hippocampal neurons (Silverman et al., 2001).
A series of chimeric and deletion AptKv3 channels were tested for their abilities to target to the distal dendrites. Swapping the C-terminal domains, but not the N-terminal domains, was fully effective in transferring the dendritic targeting signal of $A p t \mathrm{Kv} 3.3$ to the AptKv3.1 channel. Deletion of the C-terminal domains of either channel resulted in proteins that were restricted to the somatic domains, suggesting that the activity of the targeting signal in the AptKv3.3 channel is required to direct dendritic localization. In the absence of this signal, both channels were restricted to the somatic and proximal dendritic domains. Involvement of a PDZ motif-mediated interaction as part of the targeting mechanism was indicated by the finding that removal of the last three amino acids, SIL, from the $\mathrm{C}$ terminus of AptKv3.3 resulted in loss of the dendritic targeting. The C-terminal sequence of AptKv3.3 is PSIL, which matches the consensus sequence $\mathrm{X}-\mathrm{S} / \mathrm{T}-\mathrm{X}-\mathrm{L} / \mathrm{V}$ for the class I PDZ binding motif (Sheng and Sala, 2001). This result suggests that one requirement for the dendritic targeting may involve a PDZ-type protein-protein with the $\mathrm{C}$ terminus of AptKv3.3.

The presence of a C-terminal targeting signal in AptKv3.3 channels is consistent with a number of studies that have demonstrated C-terminal sequence motifs that direct channel localization. Targeting of Kv4.2 channels to the dendrites of cultured cortical neurons is directed by a 16 amino acid sequence in the C-terminal intracellular segment that contains a critical dileucine motif (Rivera et al., 2003). Mutational disruption of this motif resulted in mislocalization of Kv4.2 to the axonal regions. Another example is Kv2.1, in which a 26 residue sequence in the C-terminal region acts to restrict Kv2 channels to high-density clusters in the soma and proximal dendrites of cultured hippocampal neurons (Lim et al., 2000). Axonal targeting of Kv1 channels appears to be complex, with evidence for an axonal targeting signal in the N-terminal domain (Gu et al., 2003) that can be regulated by the binding of scaffold proteins at the $\mathrm{C}$ terminus of the channel (Arnold and Clapham, 1999; Misonou and Trimmer, 2004). For Kv3 channels, studies with polarized epithelial cells have also shown that the C-terminal intracellular segment of Kv3.2b targets the channel to the apical domain (Ponce et al., 1997). Although this result confirms the importance of the C-terminal domain in directing the localization of Kv3.2 channels, the potential role for the PXPSIL sequence in this targeting has not been examined.

The identity of the PDZ motif-containing protein that may direct AptKv3.3 targeting is unknown, but PDZ-mediated protein interactions have been demonstrated to function in the targeting of several neuronal ion channels. A well studied example is the interaction of the Kv1 potassium channels with members of the PSD-95 family of PDZ-containing proteins (Kim et al., 1995). Arnold and Clapham (1999) demonstrated that the interaction of PSD-95 with the Kv1.4 channel is necessary but not sufficient to achieve distribution of Kv1.4 to axonal domains. In this case, the interaction with PSD-95 appears to be an important permissive element that allows full expression of the axonal targeting signal located in the N-terminal T1 domain (Gu et al., 2003). Our results suggest that AptKv3.3 channels provide a new example of a PDZ motif-mediated localization process but to dendritic membranes compared with axons or synaptic terminals. Moreover, the terminal sequence PXPSIL (X, aliphatic amino acid) is present in both the teleost and mammalian Kv3.3 channel proteins and is also present at the $\mathrm{C}$ terminus of the rodent $\mathrm{Kv} 3.2 \mathrm{~b}$ channel (Ponce et al., 1997). We suggest that PXPSIL in the rodent Kv3.3 channel is also likely to be required for dendritic targeting of Kv3.3, as shown for cerebellar Purkinje cells (Rashid 
et al., 2001b; Martina et al., 2003; McKay and Turner, 2004). Additional studies are needed to determine whether the C-terminal PXPSIL sequence has similar targeting functions for both Kv3.3 and Kv3.2b channels in mammalian neurons.

\section{Physiological significance for selective targeting of AptKv3 channels}

Previous work has revealed clear distinctions in the physiological role of somatic versus dendritic Kv3 channels in ELL pyramidal cells. At the soma, high-threshold potassium channels rescue spike trains from inactivation during high-frequency discharge through two actions: one by promoting the recovery of sodium channels from cumulative inactivation and the second by preventing a cumulative activation of low-threshold potassium current (Fernandez et al., 2005). The higher level of AptKv3.1 channels in the LS segment is then consistent with the ability for cells in this map to analyze high-frequency signals (Shumway, 1989; Metzner and Juranek, 1997). AptKv3 channels also modify the threshold for a form of burst discharge that is regulated by the properties of somatic and dendritic sodium spikes (Lemon and Turner, 2000; Noonan et al., 2003). Burst threshold is determined by the relative duration of a narrow somatic spike and broad dendritic spike that promotes dendrosomatic current flow to the soma. We have shown that Kv3 channels contribute to spike repolarization at both the somatic and dendritic levels (Rashid et al., 2001a; Noonan et al., 2003). AptKv3.3-mediated repolarization of dendritic spikes increases burst threshold by decreasing the duration of the dendritic spike and thus the extent of dendrosomatic current flow. In contrast, $A p t \mathrm{Kv} 3.3$ and $A p t \mathrm{Kv} 3.1$ channels at the soma produce a very narrow somatic spike, allowing dendrosomatic current flow to excite the soma and thus lower burst threshold. The relative distribution and density of AptKv3 channels at the somatic and dendritic level are thus responsible for establishing the threshold for a burst discharge that is involved in feature extraction of sensory signals (Gabbiani et al., 1996; Oswald et al., 2004). The current work now reveals that the density for $A p t \mathrm{Kv} 3.1$ expression at the soma can be regulated independently of the dendrite and identifies the molecular mechanism that allows $A p t \mathrm{Kv} 3.3$ channels to distribute to dendritic regions to modify backpropagating spikes.

\section{References}

Arnold DB, Clapham DE (1999) Molecular determinants for subcellular localization of PSD-95 with an interacting $\mathrm{K}^{+}$channel. Neuron 23:149-157.

Berman NJ, Maler L (1999) Neural architecture of the electrosensory lateral line lobe: adaptations for coincidence detection, a sensory searchlight and frequency-dependent adaptive filtering. J Exp Biol 202:1243-1253.

Bottai D, Maler L, Dunn RJ (1998) Alternative RNA splicing of the NMDA receptor NR1 mRNA in the neurons of the teleost electrosensory system. J Neurosci 18:5191-5202.

Carr C, Maler L (1986) Electroreception in Gymnotiform fish. In: Electroreception (Bullock TH, Heiligenberg W, eds), pp 319-373. New York: Wiley.

Chenchik A, Diachenko L, Moqadam F, Tarabykin V, Lukyanov S, Siebert PD (1996) Full-length cDNA cloning and determination of mRNA 5' and 3' ends by amplification of adaptor-ligated cDNA. Biotechniques 21:526-534.

Coetzee WA, Amarillo Y, Chiu J, Chow A, Lau D, McCormack T, Moreno H, Nadal MS, Ozaita A, Pountney D, Saganich M, Vega-Saenz de Miera E, Rudy B (1999) Molecular diversity of $\mathrm{K}^{+}$channels. Ann NY Acad Sci 868:233-285.

D’Apuzzo M, Mandolesi G, Reis G, Schuman EM (2001) Abundant GFP expression and LTP in hippocampal acute slices by in vivo injection of sindbis virus. J Neurophysiol 86:1037-1042.

Devaux J, Alcaraz G, Grinspan J, Bennett V, Joho R, Crest M, Scherer SS
(2003) Kv3.1b is a novel component of CNS nodes. J Neurosci 23:4509-4518.

DiCiommo DP, Bremner R (1998) Rapid, high level protein production using DNA-based Semliki Forest virus vectors. J Biol Chem 273:18060-18066.

Ehrengruber MU, Hennou S, Bueler H, Naim HY, Deglon N, Lundstrom K (2001) Gene transfer into neurons from hippocampal slices: comparison of recombinant Semliki Forest virus, adenovirus, adeno-associated virus, lentivirus, and measles virus. Mol Cell Neurosci 17:855-871.

Erisir A, Lau D, Rudy B, Leonard CS (1999) Function of specific $\mathrm{K}^{+}$channels in sustained high-frequency firing of fast-spiking neocortical interneurons. J Neurophysiol 82:2476-2489.

Fernandez FR, Morales E, Rashid AJ, Dunn RJ, Turner RW (2003) Inactivation of Kv3.3 potassium channels in heterologous expression systems. J Biol Chem 278:40890-40898.

Fernandez FR, Mchaffey WH, Molineux ML, Turner RW (2005) High threshold $\mathrm{K}^{+}$current increases gain by offsetting a frequency-dependent increase in low threshold $\mathrm{K}^{+}$current. J Neurosci 25:363-371.

Frangioni JV, Neel BG (1993) Solubilization and purification of enzymatically active glutathione S-transferase (pGEX) fusion proteins. Anal Biochem 210:179-187.

Frolov I, Hoffman TA, Pragai BM, Dryga SA, Huang HV, Schlesinger S, Rice CM (1996) Alphavirus-based expression vectors: strategies and applications. Proc Natl Acad Sci USA 93:11371-11377.

Gabbiani F, Metzner W, Wessel R, Koch C (1996) From stimulus encoding to feature extraction in weakly electric fish. Nature 384:564-567.

Golding B, Felsenstein J (1990) A maximum likelihood approach to the detection of selection from a phylogeny. J Mol Evol 31:511-523.

Gu C, Jan YN, Jan LY (2003) A conserved domain in axonal targeting of Kv1 (Shaker) voltage-gated potassium channels. Science 301:646-649.

Jerng HH, Pfaffinger PJ, Covarrubias M (2004) Molecular physiology and modulation of somatodendritic A-type potassium channels. Mol Cell Neurosci 27:343-369.

Jiang W, Hunter T (1998) Analysis of cell-cycle profiles in transfected cells using a membrane-targeted GFP. Biotechniques 24:349-350.

Johnston D, Christie BR, Frick A, Gray R, Hoffman DA, Schexnayder LK, Watanabe S, Yuan LL (2003) Active dendrites, potassium channels and synaptic plasticity. Philos Trans R Soc Lond B Biol Sci 358:667-674.

Kim E, Niethammer M, Rothschild A, Jan YN, Sheng M (1995) Clustering of Shaker-type $\mathrm{K}^{+}$channels by interaction with a family of membraneassociated guanylate kinases. Nature 378:85-88.

Lemon N, Turner RW (2000) Conditional spike backpropagation generates burst discharge in a sensory neuron. J Neurophysiol 84:1519-1530.

Lewis A, McCrossan ZA, Abbott GW (2004) MinK, MiRP1, and MiRP2 diversify Kv3.1 and Kv3.2 potassium channel gating. J Biol Chem 279:7884-7892.

Li W, Kaczmarek LK, Perney TM (2001) Localization of two high-threshold potassium channel subunits in the rat central auditory system. J Comp Neurol 437:196-218.

Lim ST, Antonucci DE, Scannevin RH, Trimmer JS (2000) A novel targeting signal for proximal clustering of the $\mathrm{Kv} 2.1 \mathrm{~K}^{+}$channel in hippocampal neurons. Neuron 25:385-397.

Lundstrom K, Ehrengruber MU (2003) Semliki Forest virus (SFV) vectors in neurobiology and gene therapy. Methods Mol Med 76:503-523.

Lundstrom K, Rotmann D, Hermann D, Schneider EM, Ehrengruber MU (2001) Novel mutant Semliki Forest virus vectors: gene expression and localization studies in neuronal cells. Histochem Cell Biol 115:83-91.

Lundstrom K, Abenavoli A, Malgaroli A, Ehrengruber MU (2003) Novel Semliki Forest virus vectors with reduced cytotoxicity and temperature sensitivity for long-term enhancement of transgene expression. Mol Ther 7:202-209.

Maler L, Sas EK, Rogers J (1981) The cytology of the posterior lateral line lobe of high-frequency weakly electric fish (Gymnotidae): dendritic differentiation and synaptic specificity in a simple cortex. J Comp Neurol 195:87-139.

Maler L, Sas E, Carr CE, Matsubara J (1982) Efferent projections of the posterior lateral line lobe in gymnotiform fish. J Comp Neurol 211:154-164.

Maler L, Sas E, Johnston S, Ellis W (1991) An atlas of the brain of the electric fish Apteronotus leptorhynchus. J Chem Neuroanat 4:1-38.

Martina M, Schultz JH, Ehmke H, Monyer H, Jonas P (1998) Functional and molecular differences between voltage-gated $\mathrm{K}^{+}$channels of fast- 
spiking interneurons and pyramidal neurons of rat hippocampus. J Neurosci 18:8111-8125.

Martina M, Yao GL, Bean BP (2003) Properties and functional role of voltage-dependent potassium channels in dendrites of rat cerebellar Purkinje neurons. J Neurosci 23:5698-5707.

Matsukawa H, Wolf AM, Matsushita S, Joho RH, Knopfel T (2003) Motor dysfunction and altered synaptic transmission at the parallel fiberPurkinje cell synapse in mice lacking potassium channels Kv3.1 and Kv3.3. J Neurosci 23:7677-7684.

McKay BE, Turner RW (2004) Kv3 $\mathrm{K}^{+}$channels enable burst output in rat cerebellar Purkinje cells. Eur J Neurosci 20:729-739.

Metzner W, Juranek J (1997) A sensory brain map for each behavior? Proc Natl Acad Sci USA 94:14798-14803.

Misonou H, Trimmer JS (2004) Determinants of voltage-gated potassium channel surface expression and localization in mammalian neurons. Crit Rev Biochem Mol Biol 39:125-145.

Moreno H, Kentros C, Bueno E, Weiser M, Hernandez A, Vega-Saenz de Miera E, Ponce A, Thornhill W, Rudy B (1995) Thalamocortical projections have $\mathrm{K}^{+}$channel that is phosphorylated and modulated by cAMPdependent protein kinase. J Neurosci 15:5486-5501.

Noonan L, Doiron B, Laing C, Longtin A, Turner RW (2003) A dynamic dendritic refractory period regulates burst discharge in the electrosensory lobe of weakly electric fish. J Neurosci 23:1524-1534.

Oswald AM, Chacron MJ, Doiron B, Bastian J, Maler L (2004) Parallel processing of sensory input by bursts and isolated spikes. J Neurosci 24:4351-4362.

Parameshwaran S, Carr C, Perney TM (2001) Expression of Kv3.1 in avian auditory brainstem. J Neurosci 21:485-494.

Ponce A, Vega-Saenz de Miera E, Kentros C, Moreno H, Thornhill B, Rudy B (1997) $\mathrm{K}^{+}$channel subunit isoforms with divergent carboxy-terminal sequences carry distinct membrane targeting signals. J Membr Biol 159:149-159.

Rashid AJ, Dunn RJ (1998) Sequence diversity of voltage-gated potassium channels in an electric fish. Mol Brain Res 54:101-107.

Rashid AJ, Morales E, Turner RW, Dunn RJ (2001a) The contribution of dendritic $\mathrm{Kv}_{3} \mathrm{~K}^{+}$channels to burst threshold in a sensory neuron. J Neurosci 21:125-135.

Rashid AJ, Dunn RJ, Turner RW (2001b) A prominent soma-dendritic dis- tribution of $\mathrm{Kv} 3.3 \mathrm{~K}^{+}$channels in electrosensory and cerebellar neurons. J Comp Neurol 441:234-247.

Rivera JF, Ahmad S, Quick MW, Liman ER, Arnold DB (2003) An evolutionarily conserved dileucine motif in Shal $\mathrm{K}^{+}$channels mediates dendritic targeting. Nat Neurosci [Erratum (2003) 6:899] 6:243-250.

Rudy B, McBain CJ (2001) Kv3 channels: voltage-gated $\mathrm{K}^{+}$channels designed for high-frequency repetitive firing. Trends Neurosci 24:517-526.

Rudy B, Chow A, Lau D, Amarillo Y, Ozaita A, Saganich M, Moreno H, Nadal MS, Hernandez-Pineda R, Hernandez-Cruz A, Erisir A, Leonard C, VegaSaenz de Miera E (1999b) Contributions of Kv3 channels to neuronal excitability. Ann NY Acad Sci 868:304-343.

Sekirnjak C, Martone ME, Weiser M, Deerinck T, Bueno E, Rudy B, Ellisman $\mathrm{M}$ (1997) Subcellular localization of the $\mathrm{K}^{+}$channel subunit Kv3.1b in selected rat CNS neurons. Brain Res 766:173-187.

Sheng M, Sala C (2001) PDZ domains and the organization of supramolecular complexes. Annu Rev Neurosci 24:1-29.

Shumway CA (1989) Multiple electrosensory maps in the medulla of weakly electric gymnotiform fish. I. Physiological differences. J Neurosci 9:4388-4399.

Silverman MA, Kaech S, Jareb M, Burack MA, Vogt L, Sonderegger P, Banker G (2001) Sorting and directed transport of membrane proteins during development of hippocampal neurons in culture. Proc Natl Acad Sci USA 98:7051-7057.

Trimmer JS, Rhodes KJ (2004) Localization of voltage-gated ion channels in mammalian brain. Annu Rev Physiol 66:477-519.

Turner RW, Plant JR, Maler L (1996) Oscillatory and burst discharge across electrosensory topographic maps. J Neurophysiol 76:2364-2382.

Turner RW, Lemon N, Doiron B, Rashid AJ, Morales E, Longtin A, Maler L, Dunn RJ (2002) Oscillatory burst discharge generated through conditional backpropagation of dendritic spikes. J Physiol (Paris) 96:517-530.

Vega-Saenz de Miera E, Weiser M, Kentros C, Lau D, Moreno H, Serodio P, Rudy B (1994) Shaw-related $\mathrm{K}^{+}$channels in mammals. In: Handbook of membrane channels (Peracchia C, ed), pp 41-78. New York: Academic.

Wang LY, Gan L, Forsythe ID, Kaczmarek LK (1998) Contribution of the Kv3.1 potassium channel to high-frequency firing in mouse auditory neurones. J Physiol (Lond) 509:183-194.

Zupanc GK, Horschke I (1995) Proliferation zones in the brain of adult gymnotiform fish: a quantitative mapping study. J Comp Neurol $353: 213-233$. 